\title{
ESCRITA INFANTIL: A CIRCULAÇÃO DA CRIANÇA POR REPRESENTAÇÕES SOBRE GÊNEROS DISCURSIVOS
}

\author{
Cristiane Carneiro CAPRISTANO* \\ Elaine Cristina de OLIVEIRA **
}

- RESUMO: O propósito deste artigo é o de refletir sobre a circulação imaginária das crianças por representações sobre gêneros discursivos. Tem-se como objetivo mais específico investigar como a circulação por essas representações mostra-se na projeção que a criança faz de um (ou mais) destinatário(s) para o (seu) enunciado. Para a realização deste estudo, assume-se o conceito de gênero do discurso como proposto por Bakhtin (2000). Na análise dos enunciados escritos infantis selecionados, privilegiou-se um traço, essencial e constitutivo, dessa definição de gênero: o fato de os tipos relativamente estáveis de enunciados terem, sempre, um direcionamento, um endereçamento (BAKHTIN, 2000). Partindo dos conceitos de endereçamento e de outro - este último segundo a proposta de Authier-Revuz (1982, 1990) -, supõe-se que, em enunciações escritas ou faladas, o sujeito precisa negociar com os outros (outros dizeres, outros registros, outros significantes e, também, outros destinatários) que o constituem e determinam a emergência dos enunciados que produz. A análise dos enunciados infantis permitiu observar dois fatos importantes e interligados: a não univocidade e a flutuação no endereçamento desses enunciados.

- PALAVRAS-CHAVE: Aquisição da escrita. Gêneros do discurso. Relações intergenéricas.

\section{A história da água limpa.}

A água linpa tem o ingrediente da água. Os ingredientes é areia fina - areia grossa e pedra cascalio.

Para Bens Cristiane e Renata e Eduardo.

(Texto produzido por um aluno da segunda série do Ensino Fundamental)

\section{Introdução}

Enunciados como o apresentado em epígrafe, produzidos por diferentes crianças em resposta à solicitação de um pesquisador para que relatassem e/ou

\footnotetext{
* UEM - Universidade Estadual de Maringá - Departamento de Teorias Linguísticas e Literárias. Maringá - PR Brasil. 87020-900 - capristano1@yahoo.com.br

** UFBA - Universidade Federal da Bahia. Instituto de Ciências da Saúde - Departamento de Fonoaudiologia. Salvador - BA - Brasil. 40110-902 - elaine.oliveira@ufba.br
} 
descrevessem uma experiência, constituem a base de nossas reflexões. Neste estudo, partimos da seguinte constatação: a chamada aquisição da escrita infantil envolve não só a circulação imaginária das crianças por representações sobre aquilo que poderíamos designar como formas estritamente linguísticas, especialmente aquelas relacionadas ao modo de enunciação escrito - recursos ortográficos, lexicais, gramaticais, dentre outros -, mas, também, a circulação das crianças por representações ligadas a tipos relativamente estáveis de enunciados produzidos em diferentes esferas da atividade humana (BAKHTIN, 2000): a circulação, portanto, por representações sobre gêneros discursivos.

Com a utilização das noções de "representação" e de "circulação imaginária", queremos nos aproximar do modo como Corrêa (2004) entende o processo de produção de textos. Para o autor, a produção de textos seria mediada por imagens - no sentido de Pêcheux $(1990)^{1}$ - que os escreventes teriam sobre a (sua) escrita. No processo de produção de seus enunciados, os escreventes circulariam por um imaginário sobre a escrita equivalente à representação social da escrita, compreendida, por sua vez, "[...] não só como as noções prefiguradas que, em certa medida, comandam as práticas sociais (e de escrita), mas também como o modo pelo qual essas práticas cunham, não menos concretamente, os seus produtos materiais e simbólicos." (CORRÊA, 2004, p.XIX). Ou seja, para Corrêa (2004), a noção de imaginário sobre a escrita refere-se tanto ao produto das imagens construídas sobre as representações sociais da escrita, quanto ao "[...] processo de sua construção no interior das mais diversas práticas sociais." (CORRËA, 2004, p.XIX).

Se considerarmos que o chamado processo de aquisição da escrita não ocorre desvinculado de um processo de aquisição de gêneros discursivos, podemos supor que, no processo de aquisição da escrita, as crianças circulariam também por um imaginário sobre gêneros discursivos que se referiria tanto ao produto das imagens socialmente construídas sobre os gêneros, quanto ao "[...] processo de sua construção no interior das mais diversas práticas sociais." (CORRÊA, 2004, p.XIX). ${ }^{2}$

Corrêa (2004, p.XIX) salienta que a noção de imaginário - e, por conseguinte, a noção de imagem e a noção de representação (sinônimos possíveis neste contexto) - "liga-se preferencialmente aos conceitos de 'formação imaginária', 'antecipação' e de 'dominância" de certos elementos das 'condições de produção'." O autor acrescenta que "Num paralelo com o trabalho artesanal do fazedor de imagens de santos, diria que 'imaginário' refere-se tanto à exposição tendencialmente mais completa das imagens dadas como prontas quanto ao próprio trabalho de (re-)construir velhas imagens e criar novas. O termo 'imaginário' que, em seu uso arcaico, é também o nome do ofício que se ocupa desse tipo de fabricação - uma outra forma de nomear o próprio santeiro - corresponderia, pois, ao mesmo tempo, ao conjunto das imagens e ao trabalho - sempre inacabado do artesão de impor sua marca nas imagens que produz." (CORREA, 2004, p.XIX).

2 É importante salientar que a noção de imaginário sobre a escrita, tal como formulada em Corrêa (2004), contempla a noção de imaginário sobre gêneros discursivos. Dissociamos estas duas noções unicamente com o propósito de dar destaque ao que nos interessa: as imagens sobre gêneros discursivos. 
Essa circulação, certamente, não ocorre apenas quando as crianças começam o processo de aquisição formal da escrita. Não há como negar que, quando iniciam a escolarização formal, as crianças já entraram em contato, nas diversas práticas sociais orais e letradas das quais participa(ra)m, de forma direta ou indireta, tanto com gêneros secundários quanto com gêneros primários (BAKHTIN, 2000). Esse contato, muito provavelmente, permite(iu) a aquisição de uma série de saberes sobre os gêneros - saberes aqui entendidos como noções prefiguradas, socialmente edificadas, sobre os gêneros, imagens, em última instância -, ampliados com a inserção da criança na escola.

Tanto os saberes apropriados nas diversas e inúmeras práticas sociais orais e letradas das quais as crianças participaram em sua experiência pregressa à escolarização, quanto aqueles saberes que as crianças passam a "deter" no momento em que entram na escola, não podem ser medidos e quantificados de forma integral. No entanto, supomos poder encontrar indícios desses saberes nos enunciados escritos produzidos por elas. ${ }^{3}$

Neste estudo, nosso propósito é justamente examinar indícios presentes em enunciados infantis que sinalizam representações das crianças sobre gêneros discursivos. O foco será a investigação de como essas representações se mostram na projeção/antecipação que a criança (escrevente) faz de um (ou mais) destinatário(s) para o seu enunciado.

Sem, negar, portanto, outras características importantes dos gêneros discursivos, como o conteúdo temático, o estilo e a construção composicional, privilegiamos um traço, essencial e constitutivo, da definição de gênero como idealizada por Bakhtin: o fato de os tipos relativamente estáveis de enunciados terem, sempre e inevitavelmente, um direcionamento, um endereçamento:

[...] o direcionamento, o endereçamento do enunciado é sua peculiaridade constitutiva sem a qual não há nem pode haver enunciado. As várias formas típicas de tal direcionamento e as diferentes concepções típicas de destinatários são peculiaridades constitutivas e determinantes dos diferentes gêneros do discurso. (BAKHTIN, 2000, p.305, grifo nosso).

Assim, para Bakhtin, os diversos tipos relativamente estáveis de enunciados só podem ser compreendidos se considerarmos que sempre se direcionam a "alguém", ou, de forma mais precisa, se considerarmos que a vida de um enunciado, sua composição e seu estilo dependem e estão intimamente entrelaçadas ao modo como o falante e/ou o escrevente "percebe e representa para si os seus destinatários" (BAKHTIN, 2000, p.301).

3 A respeito da relevância dos indícios na investigação científica do processo de aquisição da escrita pelas crianças, conferir, especialmente, os trabalhos de Abaurre, Fiad e Mayrink-Sabinson (1997, 2003). 
Esse "alguém" ou, ainda, esses "destinatários" podem, para Bakhtin (2000, p.301), ser "o participante-interlocutor direto do diálogo cotidiano", "um público mais ou menos diferenciado", "uma coletividade diferenciada de especialista de algum campo especial da comunicação cultural", um "povo", o "subordinado", o "chefe"... ou, ainda, "um outro totalmente indefinido, não concretizado". São, enfim, "modalidades" " "concepções de destinatário", determinadas "pelos campos da atividade humana e da vida" a que os enunciados se referem (BAKHTIN, 2000, p.301).

À luz dessas afirmações, não parece equivocado presumir que, embora o destinatário do enunciado possa "[...] coincidir pessoalmente com aquele (ou aqueles) a quem responde o enunciado." (BAKHTIN, 2000, p.301), não é necessariamente o destinatário como interlocutor empírico que é contemplado na noção de endereçamento de que trata Bakhtin. Em sua reflexão, ganha saliência o caráter típico desse endereçamento, já que a antecipação/projeção do destinatário é uma exigência da enunciação, e os destinatários, desde o princípio, são previstos pelo tipo relativamente estável de enunciado que organiza, dirige e/ou possibilita a enunciação. Os destinatários são assim considerados presença constitutiva e determinante do enunciado do escrevente, elemento do gênero do discurso que guia a (sua) enunciação.

As afirmações precedentes também abrem a possibilidade para pensar o destinatário como um outro (a exemplo do que Authier-Revuz apresenta em trabalhos como os de 1982 e 1990) com o qual o sujeito falante e/ou escrevente negocia (obrigatoriamente) no momento da produção de (seus) enunciados. Ou seja, estamos supondo que, em suas enunciações escritas ou faladas, o sujeito precisa negociar com os outros (outros dizeres, outros registros, outros significantes e, também, outros destinatários) que o constituem e determinam a emergência dos enunciados escritos ou falados que produz. A imagem desses outros/destinatários não são, pois, figuras exteriores, molduras para os enunciados produzidos pelo sujeito, mas, sim, elementos constitutivos desses enunciados.

Essa noção de outros/destinatários permeia as reflexões deste estudo no qual se busca compreender a circulação da criança por representações sobre gêneros discursivos.

\section{Sobre o material de análise}

Conforme adiantamos, selecionamos, para este estudo, enunciados escritos produzidos por diferentes crianças em resposta à solicitação de um pesquisador para que relatassem e/ou descrevessem uma experiência. Esses enunciados 
compõem um dos bancos de produções textuais sobre a aquisição da escrita infantil do Grupo de Pesquisa "Estudos sobre a Linguagem" (CNPq/Unesp). Nesse banco, foram coletados, quinzenalmente, entre abril de 2001 e dezembro de 2004, textos (enunciados escritos) produzidos por diversas crianças, sempre em contexto escolar - mais especificamente, em duas escolas públicas da rede municipal de ensino da cidade de São José do Rio Preto (SP).

De um total de 61 (sessenta e um) diferentes enunciados escritos produzidos no dia 02/05/2002 - quando as crianças participantes frequentavam a segunda série do ensino fundamental (equivalente ao atual terceiro ano) -, selecionamos 07 (sete) enunciados que, num primeiro olhar, foram considerados mais singulares pelo modo como respondiam à solicitação do pesquisador. Esses enunciados decorreram de uma proposta de produção textual desenvolvida da maneira que se segue, de forma adaptada, considerando-se os propósitos deste artigo.

No dia da coleta, o pesquisador fez, junto com as crianças, uma experiência que reconstituía parcialmente um processo de purificação da água. Contou para as crianças que havia retirado de um livro didático os procedimentos para a realização dessa experiência. Durante a realização desses procedimentos, o pesquisador solicitou que as crianças prestassem atenção, uma vez que elas deveriam, posteriormente, descrever a experiência em questão. Terminada a experiência, no momento da produção dos enunciados escritos, o pesquisador pediu às crianças que contassem como havia sido feita a experiência de forma que uma terceira pessoa (que não estivesse na sala de aula) pudesse ler e repetir todas as etapas e chegar, como ocorreu na experiência realizada junto com eles, ao resultado esperado.

\section{A proposta de produção textual}

Para que as crianças realizassem a atividade de acordo com as exigências feitas pelo pesquisador, elas precisariam, primeiramente, apreender o tipo relativamente estável de enunciado solicitado por ele. Essa tarefa pode ser considerada complexa, uma vez que é difícil definir com exatidão, a partir da instrução para produção textual descrita, o gênero discursivo solicitado pelo pesquisador: um relato escrito, um enunciado tipicamente descritivo, um enunciado tipicamente injuntivo, uma mistura de alguns desses ou de outros tipos relativamente estáveis de enunciados?

Inegavelmente, o gênero solicitado pelo pesquisador e os enunciados infantis que emergiram dessa solicitação são gêneros escolares, já que foram solicitados e produzidos na escola, como parte das atividades de aula e com o acompanhamento 
das professoras responsáveis pelas turmas. Conforme relato do pesquisador responsável pela coleta, essas professoras, muitas vezes, intervinham na produção dos enunciados com sugestões, respondendo a dúvidas pontuais das crianças sobre como escrever.

Embora válida e necessária, a classificação gênero escolar, por si só, não dá conta das especificidades da proposta textual apresentada, nem mesmo dos enunciados infantis dela derivados. Por esta razão, optamos por fazer conjecturas a respeito do tipo relativamente estável de enunciado escolar que supomos ter sido solicitado pelo pesquisador, numa tentativa de circunscrever características que julgamos constituí-lo e que podem (ou não) ter sido observadas pelas crianças.

Assim sendo, parece-nos que o tipo relativamente estável de enunciado solicitado alude a uma conjunção entre um enunciado tipicamente descritivo e um enunciado tipicamente injuntivo. O primeiro suporia uma cena em que o sujeito/produtor estaria mais voltado para a tentativa de fazer o outro/ destinatário notar elementos de um dado objeto de discurso (no caso, a realização de uma experiência). Os enunciados caracteristicamente injuntivos, por sua vez, suporiam uma cena na qual o "efeito pretendido" pelo sujeito/ produtor seria o de fazer o outro/destinatário agir de certo modo e/ou em uma determinada direção.

O caráter descritivo da instrução dada pelo pesquisador emerge mais explicitamente: ele enuncia que as crianças deveriam descrever/relatar a experiência. O caráter injuntivo, por sua vez, emerge do fato de o pesquisador ter solicitado que a descrição e/ou o relato permitisse a uma terceira pessoa repetir a experiência em questão - e, portanto, o relato/descrição deveria fazer com que o outro/destinatário estabelecido pela criança agisse de certo modo e/ou em determinada direção.

A instrução dada pelo pesquisador às crianças abre, ainda, dentre outras, a possibilidade de interpretação do gênero solicitado como um gênero com estrutura predominantemente narrativa, uma vez que aparece, na instrução, explicitamente, a seguinte afirmação: "[...] o pesquisador pediu às crianças que contassem como havia sido feita a experiência de forma que uma terceira pessoa [...]"

Destaca-se, também, que, para realizarem a atividade de acordo com as exigências feitas pelo pesquisador, as crianças deveriam observar que o tipo relativamente estável de enunciado solicitado exigia a criação, por escrito, de uma interlocução explícita entre, minimamente, duas figuras: uma em que a criança representasse a si mesma, como aluno(a) que assistiu e/ou participou de uma atividade em que foi reproduzida uma experiência e que, 
portanto, detinha conhecimentos necessários para descrevê-la; outra em que representasse um outro/destinatário, uma pessoa que não tivesse participado da atividade em que a experiência em questão foi produzida e que, portanto, não detinha, por um lado, conhecimentos necessários para descrevê-la e, por outro, conhecimentos sobre o espaço-tempo em que foi realizada aquela experiência.

Por essas razões, os enunciados deveriam, idealmente, distanciar-se do evento do qual emergiram, o que implicaria, dentre outros aspectos, o apagamento de elementos do espaço-tempo da enunciação concreta, como, por exemplo, o fato de que seus enunciados se dirigiam não a "uma terceira pessoa qualquer", mas a uma pessoa em particular: o pesquisador, que era quem de fato leria os enunciados escritos por elas.

Por fim, acreditamos que as crianças, também idealmente, deveriam observar que a escritura do enunciado não constituía uma tarefa eminentemente escolar e, portanto, não precisaria seguir padrões e/ou normas característicos desse tipo de atividade, já que a instrução para produção textual requeria que as crianças entrassem no jogo enunciativo proposto pelo pesquisador, ou seja, requeria uma simulação, uma "ficcionalização" de que estavam realizando uma atividade não escolar.

\section{A criança e seus "outros": análise dos enunciados escritos infantis}

É fundamental destacar que, neste estudo, não nos detemos na análise relativa à adequação dos enunciados infantis ao que foi solicitado pelo pesquisador, nem mesmo na análise da adequação dos recursos linguísticos mobilizados pela/na criança ao tipo relativamente estável de enunciado no qual ela parece predominantemente ter se apoiado para escrever. ${ }^{4}$ Essa opção teórico-metodológica liga-se aos objetivos, na medida em que o interesse não é o de avaliar positiva ou negativamente esses enunciados, mas tão somente analisar escolhas linguísticas decorrentes, ao menos em parte, da antecipação que a criança faz do outro/destinatário e do modo como essas escolhas permitem observar a mobilização de diferentes representações concernentes aos tipos relativamente estáveis de enunciados. Passemos, então, a destacá-las:

4 Para uma crítica à ideia de adequação relacionada ao ensino da escrita, confira Corrêa (2007). 
Figura 1 -A mágica

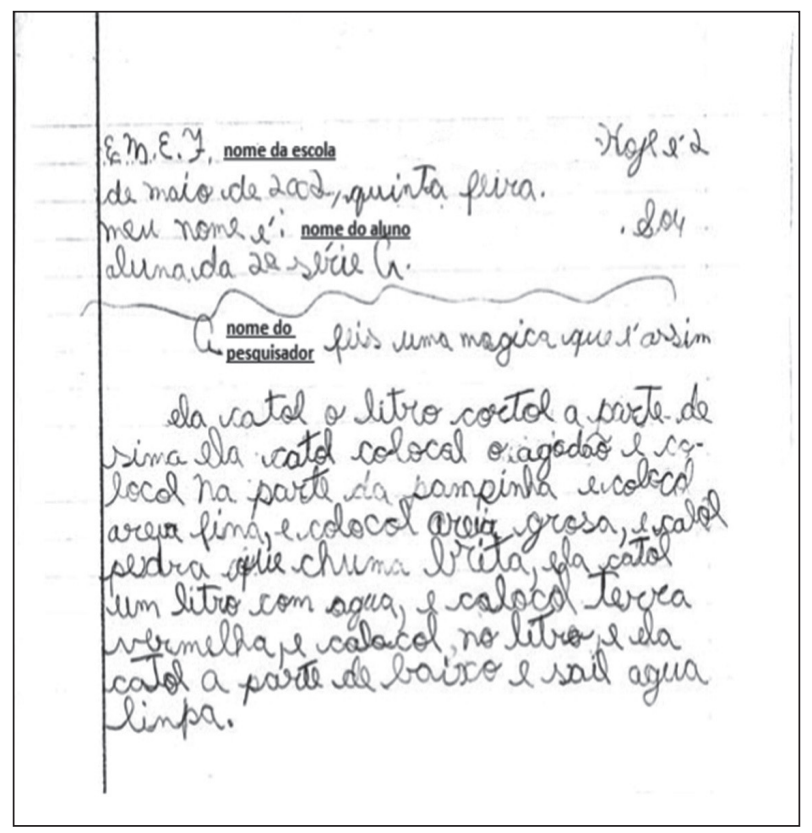

Fonte: Dados da pesquisa.

Como adiantamos, as crianças, idealmente, teriam que observar que a escritura do enunciado solicitado pelo pesquisador não constituía uma tarefa eminentemente escolar e, portanto, não precisaria seguir padrões característicos desse tipo de atividade, como, por exemplo, a inserção de um cabeçalho com informações como nome da escola, data, nome e série do aluno etc.

Não foi o que aconteceu nesse enunciado, iniciado com um cabeçalho. A presença desse cabeçalho constitui uma pista do endereçamento desse enunciado: nesse momento de seu "projeto de dizer", o escrevente estabelece como outro/destinatário a instituição escolar, respondendo a uma demanda de gêneros tipicamente escolares, já que, como sabemos, iniciar redações escolares com esse tipo de cabeçalho é uma prática comum, incentivada e cobrada pela escola.

Convém notar, entretanto, que esse endereçamento não se mantém no restante do enunciado produzido pela criança. Vemos, na tentativa da criança de descrever/relatar o que uma terceira pessoa ("A" + "nome do pesquisador") faz para construir "uma mágica", aspectos característicos de outros gêneros discursivos, mais especificamente de enunciados relativamente estáveis que têm como traço a dependência ao contexto de enunciação. 
Explicando melhor: no enunciado produzido pela criança, consta o seguinte trecho "ela catol o litro...". O destaque em negrito constitui uma expressão nominal definida que, nesse enunciado, deveria ser interpretada referencialmente. No entanto, não existe, no enunciado, um antecedente (ou subsequente) designado de forma explícita. A expressão "o litro" parece apontar para um elemento presente na situação concreta de enunciação em que havia "um litro" que seria utilizado para a realização de uma "mágica". O mesmo ocorre com o fragmento "o agodão". Este tipo de utilização da expressão nominal definida ocorre, sobretudo, em enunciados que têm como característica a dependência ao contexto de enunciação, como, por exemplo, enunciados orais do tipo diálogo face a face ou enunciados escritos como bilhetes etc. em que ouvinte e falante ou escrevente e leitor compartilhariam a mesma situação de enunciação e, deste modo, poderiam para ela apontar. Presentes na escrita da criança, esses trechos indiciam a circulação da criança por representações sobre um gênero que tem como característica a dependência ao contexto de enunciação e que supõe um outro/destinatário representado pelo "participante-interlocutor direto do diálogo cotidiano" (BAKHTIN, 2000).

A presença dessas expressões nominais definidas também indicia que, no momento de sua enunciação, a criança contaria "[...] não só com o conhecimento que supõe partilhado com seu leitor, mas também com a projeção espacial (no espaço gráfico) de um gesto indicativo dessa partilha (o de apontar para a situação concreta de enunciação)." (CORRÊA, 2004, p.05). É por acreditar estar plasmado em sua escrita o contexto em que foi produzido o (seu) enunciado que a criança refere-se a "o litro" e a "o algodão" sem, no entanto, os ter mencionado precedentemente ou os mencionar subsequentemente.

Tanto o cabeçalho quanto as expressões nominais definidas presentes nesse enunciado constituem pistas da circulação da criança por representações sobre gêneros discursivos e, mais especificamente, pistas da não univocidade do endereçamento de seu enunciado. Juntas, colocam em cena a heterogeneidade, a complexidade desse enunciado e sua constituição fundada em relações (sempre dialógicas) intergenéricas, uma vez que cada uma dessas pistas linguísticas pode ser interpretada como uma ruína de um gênero discursivo, no sentido de Corrêa (2006). O termo "ruína" não é usado aqui, muito menos em Corrêa (2006), em sua acepção negativa, com o sentido de "gêneros discursivos em estado de destruição". Pelo contrário, essas ruínas seriam "[...] partes mais ou menos informes de gêneros discursivos, que, quando presentes em outro gênero, ganham o estatuto de fontes históricas - retrospectivas ou prospectivas - da constituição de uma fala ou de uma escrita." (CORRÊA, 2006, p.209). ${ }^{5}$

5 Poder-se-ia indagar se o cabeçalho de fato constituiria uma ruína de um gênero discursivo (a redação escolar) ou, contrariamente, constituiria um gênero discursivo independente. Optamos por considerá-lo como uma ruína porque acreditamos que ele constitui parte de diferentes enunciados (cartas, ofícios, e-mails, redações 
A expressão "ruínas de gêneros discursivos" pode, a nosso ver, ser lida, alternativamente, como "fragmentos", "ecos", "lembranças" de "enunciados genéricos" e/ou "gêneros discursivos" que, presentes na escrita das crianças bem como em outras escritas -, indiciariam um imaginário sobre gêneros discursivos, ou seja, indiciariam representações que as crianças fariam dos modos relativamente estáveis com os quais enunciamos nas nossas diversas práticas sociais.

O exemplo a seguir (Figura 2) tem um funcionamento bastante semelhante ao exemplo anterior (Figura 1) e colabora para reafirmar as considerações feitas até o momento. Vejamos:

Figura 2 - Ela e a experiência

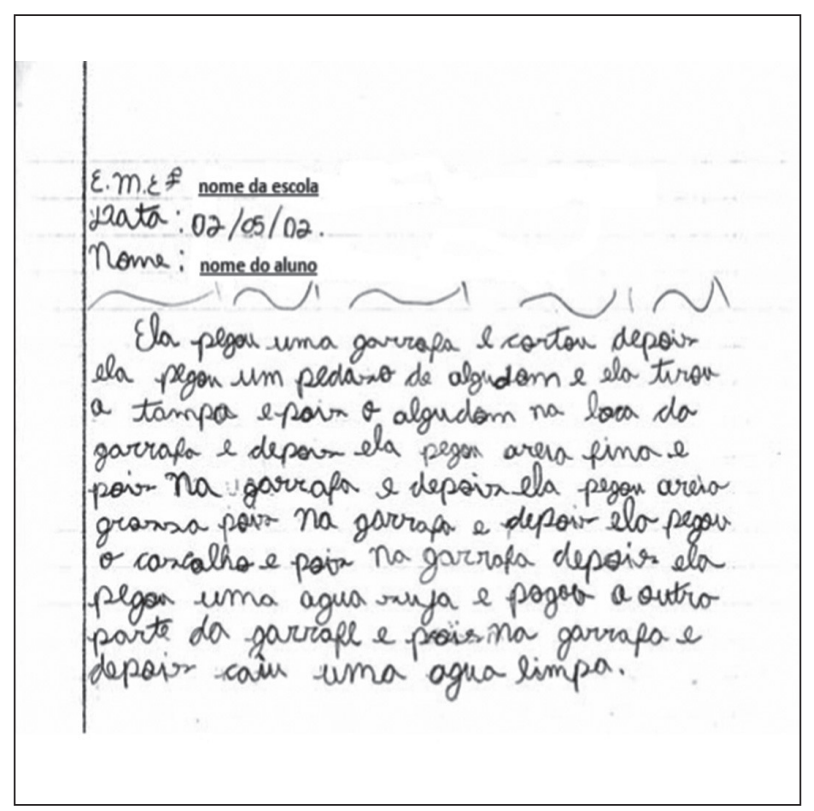

Fonte: Dados da pesquisa.

Nesse enunciado, observamos a presença do mesmo tipo de cabeçalho. Nele há, também, a utilização recorrente do pronome "ela" que poderia ser igualmente considerado índice da presença de enunciados que têm como característica a dependência ao contexto de enunciação. Assim como as expressões definidas analisadas antes, esse pronome deveria ser interpretado referencialmente, embora

escolares etc.) com os quais a criança tem contato, direta ou indiretamente. Tendo em vista que dificilmente o cabeçalho aparece sozinho nessas práticas, ele não poderia constituir gênero discursivo independente. 
não exista, no enunciado produzido pela criança, um antecedente (ou subsequente) ao qual "ela" faça referência. Mais uma vez, a criança parece contar com um conhecimento que supõe partilhado com o outro/destinatário - representado pelo "participante-interlocutor direto do diálogo cotidiano" (BAKHTIN, 2000): a situação de enunciação em que, de fato, poderíamos identificar a quem "ela" se refere.

Outros dois fatos podem indicar que, nesse enunciado, a criança supõe compartilhar a situação de enunciação com o outro/destinatário: (i) a presença da expressão definida "o cascalho" sem referente textual explícito; e (ii) a ausência de elementos que possam conduzir o leitor ao assunto sobre o qual trata a criança fatos estes que, novamente, podem ser interpretados como ruínas de um gênero discursivo tal como o diálogo cotidiano entre pessoas que se conhecem.

Os dois enunciados apresentados tornam patentes, a nosso ver, que parte das escolhas linguísticas feitas por essas crianças foi determinada pelo duplo endereçamento de seus enunciados: ora voltados para o outro/destinatário representado pela instituição escolar, ora voltados para o outro/destinatário representado pelo "participante-interlocutor direto do diálogo cotidiano", um "alguém" com o qual se supõe compartilhar a situação de enunciação. Se essa hipótese for corroborada, mudanças nas representações mobilizadas nas/pelas crianças de seus outros/destinatários ocasionariam, também, mudanças nos seus enunciados. É o que parece ocorrer no enunciado que segue:

Figura 3 - A experiência do nosso dia

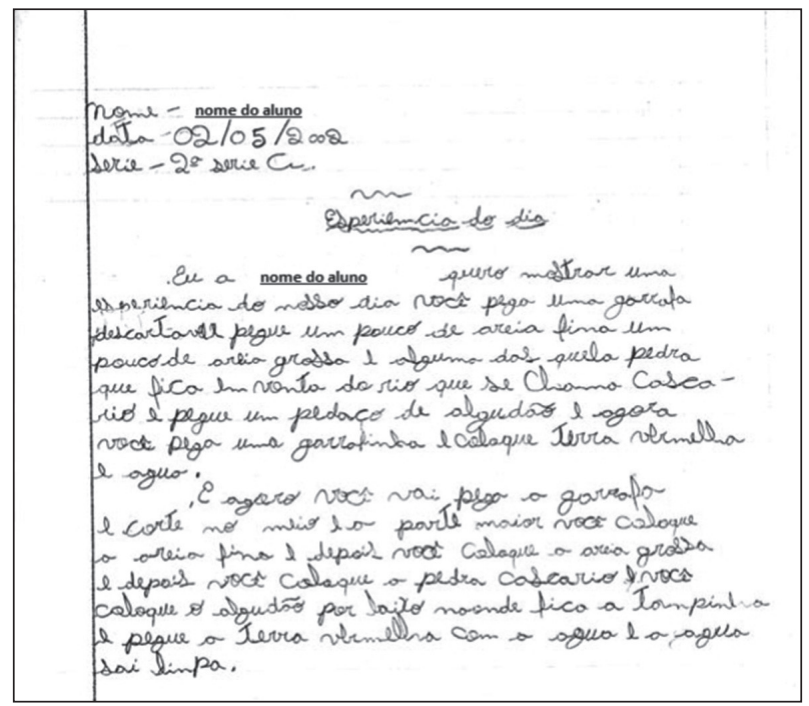

Fonte: Dados da pesquisa. 
Nesse enunciado, há, também, um duplo endereçamento, indiciado, por um lado, pela presença de elementos constitutivos do cabeçalho escolar e, por outro, pela presença de uma cena diferente daquela que vimos nos exemplos anteriores.

Essa cena refere-se à simulação de uma interlocução entre duas figuras: uma em que a criança representa a si mesma - "Eu a [nome da criança] quero mostrar uma esperiencia do nosso dia [...]" - e outra em que representa um outro/ destinatário - o você do enunciado infantil. Na representação de si mesma, contrariamente ao que parecia ter sido exigido pelo tipo de instrução dada pelo pesquisador, a criança não se representa como um(a) aluno(a) que assistiu e/ou participou de uma atividade em que foi reproduzida uma experiência, mas como uma pessoa que tem autoridade e que detém conhecimentos para ensinar os procedimentos necessários para a realização diária de uma experiência - "Eu a [nome da criança] quero mostrar uma esperiencia do nosso dia [...]". Em contrapartida, representa o outro/destinatário como alguém que, possivelmente, acompanha e recebe instruções para a realização de uma experiência, passo a passo e em tempo real, semelhante ao funcionamento de auditórios constituídos para programas televisivos nos quais são ensinadas peças de artesanato ou receitas culinárias. Um fato que ratifica essa última afirmação é o uso reiterado do pronome "você" no enunciado produzido pela criança.

Komesu (2003) faz considerações sobre o funcionamento desse pronome em páginas eletrônicas pessoais (home pages) que acreditamos convergirem para o que supomos acontecer com o enunciado infantil. Para a autora, o uso do pronome "você" nas home pages (tipo relativamente estável de enunciado) "[...] cumpre a função de simulação de uma intimidade entre escrevente e leitor que se desconhecem." (KOMESU, 2003, p.245-246) uma vez que "O escrevente que identifica o leitor como 'você' amplia o raio de abrangência de seu texto, pela utilização de uma designação de ordem genérica." (KOMESU, 2003, p.246). Ademais, citando Brandão (1998), a autora considera que

[...] o 'você' é uma representação que, distinta do 'eu', pode ganhar uma ilusória identidade no processo de alocução. O título de 'ilusória identidade' justifica-se pelo emprego de uma máscara de tratamento personalizante. No caso do texto publicitário, analisado por Brandão, essa máscara visa a um interlocutor anônimo, ou seja, qualquer um que leia o texto [...]. (KOMESU, 2003, p.246).

O mesmo tipo de utilização do pronome "você" observado em textos de internautas analisados por Komesu (2003) e em enunciados publicitários analisados por Brandão (apud KOMESU, 2003) podem aparecer também em programas televisivos nos quais são ensinadas peças de artesanato ou receitas culinárias e com os quais as crianças podem ter contato, se se considerar que muitas mães ou pessoas que fazem as vezes do responsável pelas crianças 
são potenciais telespectadores dessas emissões em horários matutinos ou vespertinos, mantendo os aparelhos televisivos ligados enquanto cumprem tarefas domésticas e tarefas como as de cuidar de crianças antes ou depois da escola. A presença, no texto da criança, do pronome "você", na medida em que sinaliza o endereçamento desse enunciado a um outro/destinatário anônimo e, possivelmente, espectador de programas de televisão - "[...] uma coletividade diferenciada [...] de algum campo especial da comunicação cultural." (BAKHTIN, 2000, p.301) -, pode ser interpretada como "ruína" desses tipos relativamente estáveis de enunciados.

Mas não só a presença do uso reiterado de "você" indicia o endereçamento desse enunciado a esse outro/destinatário. A escolha do marcador temporal "e agora", utilizado em dois momentos do enunciado da criança, também parece decorrer, ao menos em parte, da representação que a criança faz do outro/ destinatário, já que esse marcador sinaliza a simultaneidade desse enunciado com o tempo/momento em que ocorre.

Por fim, resta destacar o papel das formas verbais "pegar" , "colocar" e "cortar" conjugadas, nesse enunciado, no imperativo afirmativo ("pega" " pegue", "coloque" e "corte"). Para tanto, será necessária uma breve digressão para entender aspectos do funcionamento dessas formas verbais no português brasileiro (PB).

Com relação ao imperativo, de acordo com Scherre (2005, 2007), há, no PB, formas em variação: nas regiões Sul, Centro-Oeste e Sudeste, ${ }^{6}$ há predomínio do imperativo associado ao indicativo ("pega", "coloca" e "corta"), enquanto que, em regiões como a Nordeste, há predomínio das formas associadas ao subjuntivo ("pegue", "coloque" e "corte"). Esse predomínio não impede, é claro, o convívio entre essas formas nas diferentes regiões. Segundo a autora, em regiões como a Sudeste, pode haver flutuação se considerarmos, por exemplo, o grau de formalidade e/ou a natureza mais ou menos dialogal do evento discursivo em que formas imperativas aparecem. Assim, eventos de fala menos formais e de natureza explicitamente mais dialogal (como o diálogo face a face) favoreceriam o aparecimento de formas como "deixa", "pega" e "corta" enquanto que eventos de fala mais formais e de natureza explicitamente menos dialogal (como a conferência acadêmica) favoreceriam o aparecimento de formas como "deixe", "pegue" e "corte" (SCHERRE, 2007).

Scherre $(2005,2007)$ assinala, também, a existência de predomínio das formas do imperativo associadas ao subjuntivo na escrita "sem diálogo" - na qual inexistem sinais da presença de discurso direto -, predomínio ligado ao propósito de assegurar uma "leitura mais diretiva" e a adequada interpretação imperativa dos enunciados dessa escrita, já que o uso da forma indicativa poderia, no texto

6 Lembramos que os dados analisados neste estudo foram coletados na região Sudeste. 
escrito "sem diálogo", desfavorecer uma interpretação das formas verbais como imperativas, ou seja, com a função de persuadir, sugerir, aconselhar etc.

De posse dessas informações, podemos presumir, por um lado, que, no enunciado apresentado na Figura 3, o verbo "pegar", conjugado como "pega", é índice (ruína, eco, lembrança...) de um enunciado que supõe um outro/destinatário anônimo, espectador, que divide com o escrevente/falante o momento da enunciação e, ainda, um enunciado tipicamente menos formal e de natureza mais dialogal. Por outro lado, os verbos "pegar", "colocar" e "cortar" conjugados como "pegue", "coloque" e "corte" são índices (ruína, eco, lembranças...) de um enunciado que supõe um outro/destinatário anônimo, mas não espectador, que não divide com o escrevente/falante o momento da enunciação, enunciado como as receitas culinárias escritas que supõem um outro/destinatário que recebe, sempre num momento posterior, instruções sobre como preparar uma receita, de modo mais formal e de natureza explicitamente menos dialogal.

No enunciado apresentado na sequência (Figura 4), é possível observar funcionamento semelhante:

Figura 4 - Uma experiência

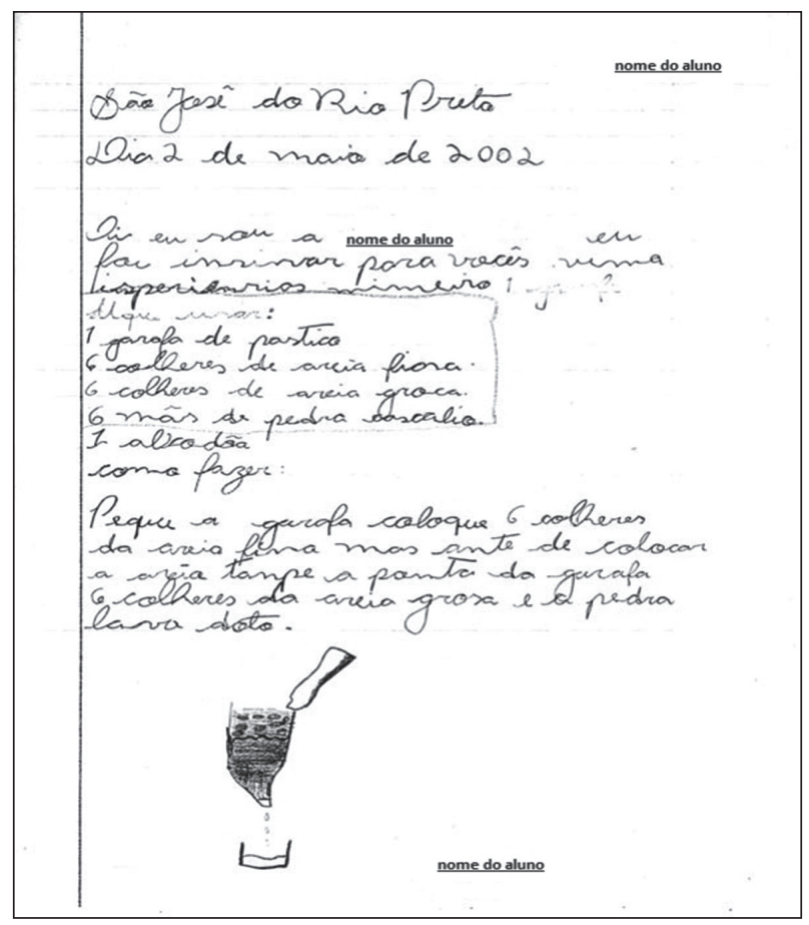

Fonte: Dados da pesquisa. 
Observam-se, nesse enunciado, ecos, lembranças e/ou ruínas de diferentes tipos relativamente estáveis de enunciados:

(a) a presença de fragmentos constitutivos do cabeçalho escolar sinalizando, novamente, o endereçamento desse enunciado a um outro/destinatário representado pela instituição escolar;

(b) a presença de apresentação pessoal ("Oi eu sou a [nome do aluno] eu fou...") e a utilização do pronome de segunda pessoa do plural "vocês" indiciando a presença de enunciados relativamente estáveis que preveem um outro/destinatário anônimo e, possivelmente, espectador de programas de televisão, "[...] uma coletividade diferenciada de algum campo especial da comunicação cultural." (BAKHTIN, 2000, p.301), um "alguém" que acompanha e recebe instruções (on-line), para a realização de, por exemplo, uma receita culinária;

(c) a presença de elementos da estrutura composicional e do estilo característicos de receitas culinárias, sobretudo escritas, que acreditamos supor um outro/ destinatário anônimo, não espectador e que não divide com o escrevente/falante o momento da enunciação. Esses fragmentos são representados pela apresentação de uma lista de itens que deveriam ser usados para a realização da experiência e de uma explicação parcial e lacunosa sobre como a experiência deveria ser realizada ("como fazer"). Destacam-se, também, a distribuição gráfica das informações e a utilização dos verbos "pegar", "colocar" e "tampar" conjugados como "pegue", "coloque" e "tampe";

(d) a presença de uma explicação parcial e lacunosa sobre o "como fazer" indiciando um outro/destinatário representado pelo "participante-interlocutor direto do diálogo cotidiano". Na apresentação do "como fazer", a criança não consegue manter-se no jogo enunciativo criado no início do enunciado e apresenta "fissuras" que poderiam ser preenchidas pelo outro/destinatário que, naquele momento, perceberia e representaria para si: o pesquisador e/ou a professora, pessoas, de fato, presentes no momento/tempo da enunciação. A incompletude do "como fazer" é uma ruína que causa um "problema de coesão", ligado à progressão textual, mas que, para este estudo, é, também, vestígio do endereçamento desse enunciado, direcionado também a um outro/destinatário com o qual a criança supõe compartilhar o tempo/momento da enunciação.

As ruínas mencionadas em (c) parecem ter sido mobilizadas pela/na criança devido à proximidade (leia-se: certa convergência entre estrutura composicional, estilo, conteúdo temático e endereçamento) do gênero "receita culinária" com o gênero que parece ter sido solicitado pelo pesquisador, que, conforme discutido, alude a uma conjunção entre uma espécie de descrição e uma espécie de injunção, características também presentes em receitas culinárias e em outros tipos relativamente estáveis de enunciados com propósitos instrucionais.

Vejamos ainda o enunciado abaixo: 
Figura 5 - Experiência e tchau

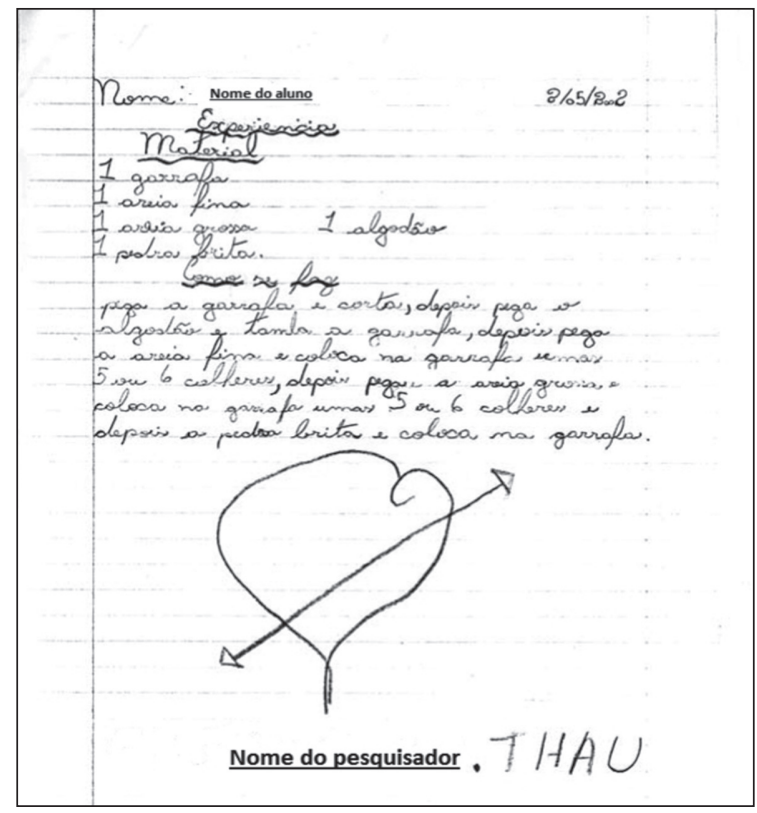

Fonte: Dados da pesquisa.

Há, aqui, novamente, elementos do cabeçalho e, em seguida, a exposição do material necessário para a realização da experiência e a descrição dos procedimentos necessários para a sua execução - no item "como se faz".

Nesse enunciado, entretanto, outra cena é construída pela criança. Não há mais a presença de apresentação pessoal e o outro/destinatário representado não está mais "on-line", acompanhando passo a passo a execução da experiência, mas, sim, ausente - receberia, assim, em um momento posterior, o enunciado produzido pela criança. A semelhança com a forma relativamente estável com que receitas culinárias e outros enunciados com propósitos instrucionais são enunciados é, novamente, inequívoca.

Observa-se também que, nesse enunciado, os verbos "pegar", "cortar", "tampar" e "colocar" são conjugados como "pega", "corta", "tampa" e "coloca". Essas formas verbais assim flexionadas admitem duas interpretações: como formas do imperativo associado ao indicativo ou, simplesmente, como formas indicativas. Neste último caso, suporiam um sujeito elíptico, "[A gente] pega a garrafa e corta..." que, por sua vez, tem o mesmo valor da primeira pessoa plural "nós" - entendida como a junção entre um "eu" e um "não eu" (BENVENISTE, 1995). Como primeira pessoa plural, "a gente" funcionaria, aqui, de forma inclusiva (BENVENISTE, 1995), ou seja, seu valor seria aferido pela junção de um "eu" que 
enuncia com um "tu/vós" ao qual o "eu" se dirige na enunciação. Em ambas as interpretações, esses verbos podem constituir índice de enunciados tipicamente menos formais e de natureza mais dialogal, orais ou escritos; sinalizariam, pois, proximidade e/ou envolvimento entre o escrevente e o outro destinatário por ele percebido e representado.

Nesse enunciado há, também, outra ruína, identificada em "Nome do pesquisador. Thau", expressão que funciona como uma espécie de recado/ despedida e constitui uma ruína de gêneros discursivos como cartas e/ou bilhetes, que geralmente contemplam esse tipo de recado ou despedida. A presença desse recado/despedida vincula o enunciado da criança à situação de sua enunciação e, portanto, indica o não apagamento de que o enunciado infantil não se dirigia a uma terceira pessoa qualquer, mas também a uma pessoa em particular, cuja leitura era esperada: ao pesquisador. Esse endereçamento ao pesquisador fica sublinhado também se se considera a presença do elemento não verbal, o coração atravessado por uma flecha, outra ruína de enunciados como as cartas e recados, sobretudo os infantis. O coração atravessado pela flecha é índice da proximidade e do envolvimento entre o escrevente e o outro/ destinatário que representa para si.

Fato bastante semelhante ocorre no exemplo seguinte (Figura 6), já apresentado na epígrafe deste estudo:

Figura 6 - A história da água limpa

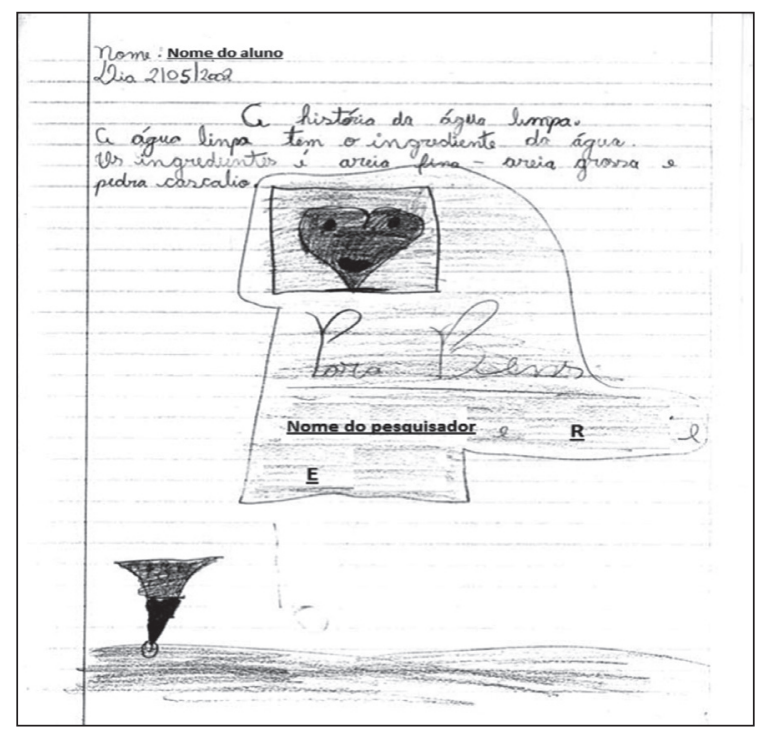

Fonte: Dados da pesquisa. 
"Para Bens nome do pesquisador e R e E" parece funcionar semelhantemente ao recado/despedida que finaliza o exemplo anterior, ou seja, constitui uma ruína de gêneros discursivos que têm como característica a finalização com recados/ despedidas, como cartas, bilhetes, cartões etc. Também essa ruína vincula esse enunciado às condições concretas de sua enunciação as quais transcendem explicitamente os limites da sala de aula, uma vez que, segundo relato do pesquisador responsável pela coleta, $\mathrm{R}$, uma das pessoas a quem o recado/ despedida se destina não estava presente no dia da coleta, mas era uma pessoa que as crianças haviam conhecido por meio do pesquisador, em outra coleta ocorrida no início do trabalho de constituição do banco de dados. "E", por sua vez, outra pessoa a quem a dedicatória se destina, é filho de " $R$ ", e as crianças tinham informações sobre ele por meio de conversas e correspondências trocadas com "R" e com o pesquisador.

Em meio a considerações a respeito de habilidades textuais de crianças em processo de alfabetização, particularmente sob a perspectiva das "funções" atribuídas ao uso da língua por crianças de diferentes camadas sociais, Soares (2003) apresenta exemplos de enunciados infantis com fatos análogos aos que observamos nos enunciados precedentes (Figuras 5 e 6). Reproduzimos um dos exemplos apresentados pela autora:

Figura 7 - A pipa

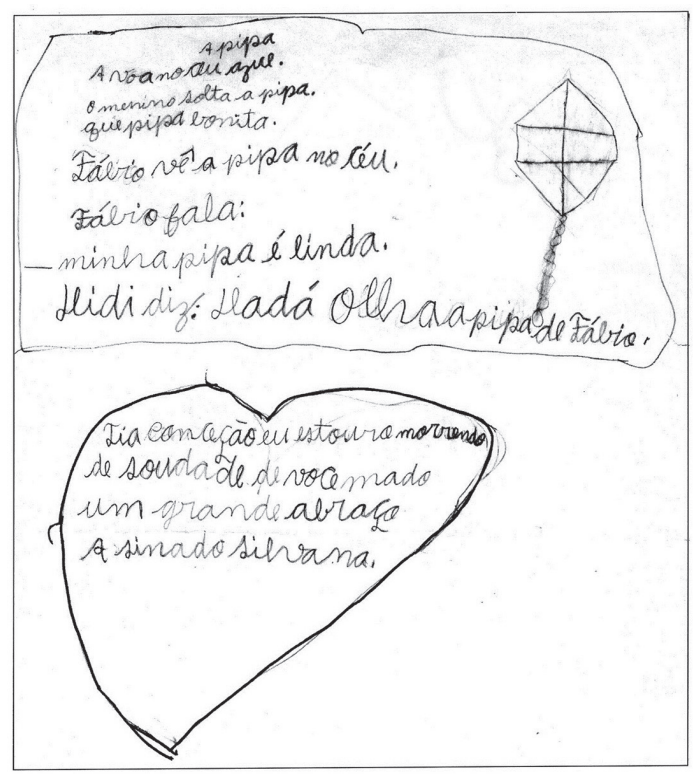

Fonte: Soares (2003, p.77). 
Nesse enunciado, a primeira parte é circundada por um retângulo e a segunda pelo desenho de um coração. Soares (2003) observa que:

[...] a separação que a criança faz entre a redação sobre a pipa, isolada em um retângulo, o bilhete à professora, circundado pelo desenho de um coração, deixa claro que ela percebe que são duas escritas diferentes: a escrita escolar, com a função instrumental de demonstrar que aprendeu a escrever o que lhe ensinaram a escrever, e a escrita não escolar, com funções pessoal e interacional. (SOARES, 2003, p.76).

Para Soares (2003), a criança estaria oscilando entre o que ela deveria escrever, respeitando o modelo imposto pela escola, e o que ela efetivamente queria escrever. De nosso ponto de vista, a criança também oscila quanto à representação do outro/destinatário que percebe e representa para si: ora escreve para o outro/destinatário representado pela instituição escolar, ora escreve para o outro/destinatário representado pela figura do professor/pesquisador. Julgamos, pois, a oscilação no endereçamento desse enunciado como fator determinante das escolhas temáticas, dos recursos lexicais, estilísticos e gráficos (no caso do retângulo e do coração) realizados pela criança.

Analogamente, em nossos exemplos, parece haver uma tensão entre dirigirse ao solicitado pelo pesquisador (relatar, descrever ou contar como havia sido feita uma experiência) e dirigir-se às pessoas que, para a criança, de fato leriam sua produção escrita: R, E e, também, o pesquisador. Essa oscilação e/ou tensão delimita as escolhas linguísticas possíveis para as crianças e essas "escolhas" acabam por se tornar ruínas de gêneros discursivos ou, mais especificamente, fontes históricas da escrita dessas crianças (CORRÊA, 2006).

Particularmente no exemplo apresentado na Figura 6, além do recado/ despedida, chama-nos, ainda, a atenção, a presença de outra ruína: o título do enunciado "A história da água limpa". Nesse título, vê-se uma referência a um fazer textual, o que poderíamos interpretar como recurso metaenunciativo. Corrêa (2006, p.212) analisa um excerto com funcionamento bastante semelhante, o qual pode ajudar a entender melhor essa ruína: "Essa história começa com uma família que vai a uma ilha passar suas férias".

Para Corrêa (2006), esse excerto marcaria uma referência, feita por sua autora - uma menina de 10 anos $^{7}$-, ao próprio fazer textual, uma reprodução de uma "referência ao fazer narrativo" (CORRÊA, 2006, p.213) e constituiria, pois, recurso metaenunciativo. $\mathrm{Na}$ análise do autor, essa referência ao fazer narrativo seria indicativa de saberes da criança sobre esse fazer. Em nosso caso, esse recurso metaenunciativo - ruína de enunciados relativamente estáveis

Esse excerto foi recolhido por Corrêa (2006) de um texto atribuído a uma menina de 10 anos, o qual consta de questão discursiva do ENC/2001 (Exame Nacional de Cursos) da área de Letras-Linguística. 
tipicamente narrativos -, além da referência a saberes ligados ao fazer narrativo, alude/responde, também, ao "contar" que aparece entremeado à instrução dada pelo pesquisador para a produção escrita das crianças. Como adiantamos, a instrução dada pelo pesquisador às crianças abria, dentre outras, a possibilidade de interpretação do gênero solicitado pelo pesquisador como sendo algo semelhante ao contar, uma vez que aparece, na descrição, explicitamente, a seguinte afirmação: "[...] o pesquisador pediu às crianças que contassem como havia sido feita a experiência de forma que uma terceira pessoa [...]".

Ademais, a utilização desse recurso metaenunciativo coloca em evidência o endereçamento do enunciado apresentado na Figura 6. O outro/destinatário que a criança percebe e representa para si parece ser a instituição escolar, visto que é muito comum, nas atividades de produção escrita escolar, priorizarem-se enunciados narrativos, recontos e reescritas de histórias contadas e lidas para as crianças, o que faz com que, para boa parte das crianças, escrever para a professora seja equivalente a escrever (narrar) uma história.

Embora de forma diferente, essa resposta/alusão ao contar está presente também no exemplo a seguir. Vejamos:

Figura 8 -A experiência da professora

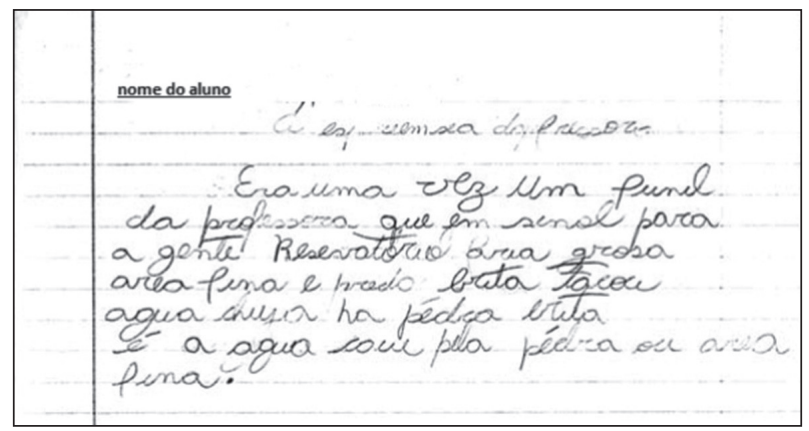

Fonte: Dados da pesquisa.

Nesse enunciado, a criança dialoga com histórias populares - geralmente orais - e/ou com histórias de livros infantis que, em um número significativo de vezes, iniciam-se com a estrutura canônica "Era uma vez...", recurso que coloca em cena a temporalidade indefinida dessas histórias. Na sequência, há uma aparente "descontinuidade": a criança não consegue seguir com o "projeto de dizer" e acaba fazendo uma enumeração de etapas para a execução da experiência. A nosso ver, a criança estaria oscilando entre contar uma história à moda dos contos de fadas ou seguir a solicitação do pesquisador: relatar e/ ou descrever uma experiência. Ela estaria, pois, na fronteira entre o relatar e 
o contar. Nessa oscilação, vemos, novamente, pistas do duplo endereçamento desse enunciado, voltado, ao mesmo tempo, para o outro/destinatário representado pela instituição escolar (escrever, na escola, é escrever histórias para "a professora") e para o outro/destinatário representado pelo "participanteinterlocutor" direto da criança, o pesquisador.

\section{Considerações finais}

Neste estudo, escolhemos, deliberadamente, não avaliar positiva ou negativamente os enunciados escritos selecionados para análise. Essa opção teórico-metodológica deriva do olhar lançado para esses enunciados e, de forma mais específica, para alguns fatos linguísticos que, neles, nos chamaram a atenção: um olhar que buscava não evidências de adequação dos enunciados das crianças ao solicitado pelo pesquisador, mas, sim, pistas da constituição histórica desses enunciados ou, dito de outro modo, indícios dos laços que eles mantêm com representações sociais, historicamente edificadas, sobre gêneros discursivos.

As reflexões feitas permitem indicar fatos que contribuem para entender melhor essa constituição histórica, como, por exemplo, o fato de os enunciados escritos infantis tomados como objeto de análise manterem, em todos os casos, vínculos com outros enunciados, uma vez que, como vimos, eles estão repletos de "ecos" e "lembranças" - ruínas, no sentido atribuído por Corrêa (2006) - de outros enunciados (ouvidos, lidos, falados ou escritos); trazem, inclusive, como procuramos mostrar, marcas específicas comuns a outros enunciados, ligadas ao modo como o escrevente percebe e representa para si os (seus) outros/ destinatários.

$\mathrm{Na}$ análise dos dados, pudemos observar também que, no processo de produção de enunciados escritos, as crianças precisam negociar com os outros destinatários que as constituem e determinam os enunciados escritos que produzem. Assim, o outro/destinatário percebido e representado pelo escrevente não é apenas uma "moldura" para os (seus) enunciados, figura externa, e, sim, elemento constitutivo desses enunciados e condicionante das escolhas ortográficas, gráficas, lexicais, morfológicas, sintáticas, semânticas etc. que o escrevente deve/pode fazer. Sem levar em conta um (ou mais) destinatário(s), ou seja, sem considerar a relação do escrevente "com o outro e seus enunciados (presentes e antecipáveis)" (BAKHTIN, 2000, p.304), torna-se impossível a vida e a existência de um enunciado.

A análise desenvolvida permitiu verificar, por fim, dois fatos importantes e interligados: a não univocidade e a flutuação no endereçamento dos enunciados infantis. Observou-se que, na produção de seus enunciados, as crianças não se 
dirigem a um único outro/destinatário, ou seja, elas são afetadas, ao mesmo tempo, por diferentes endereçamentos. Seus enunciados são, pois, fruto de flutuações, emergem voltados, concomitantemente, para o outro/destinatário representado pela instituição escolar, para o outro/destinatário representado pelo "participanteinterlocutor direto do diálogo cotidiano", para o outro/destinatário pesquisador e/ou a professora, dentre outros endereçamentos.

Não há como negar que o outro/destinatário "instituição escolar" sobrepõese aos demais. Em quase todos os enunciados examinados, a presença desse endereçamento é bastante efetiva e é mostrada, sobretudo, pela existência de cabeçalhos e, eventualmente, por outras marcas, como, por exemplo, a menção ao nome do pesquisador. Esse endereçamento prioritário não impede, contudo, a emergência de outros endereçamentos, que tornam o enunciado infantil híbrido e colocam em cena "[...] o dinamismo que marca a relação do sujeito com a linguagem." (CORRÊA, 2007, p.209), em especial, nos processos de constituição de gêneros discursivos nos momentos mais iniciais da aquisição da escrita.

\section{Agradecimentos}

À Prof. Dra. Fabiana Cristina Komesu e ao Prof. Dr. Lourenço Chacon pela leitura minuciosa e pelas preciosas sugestões incorporadas à versão final deste artigo. As falhas que restam são de nossa inteira responsabilidade.

CAPRISTANO, C. C.; OLIVEIRA, E. C. de. Children's writing and their imaginary circulation by the representations of discursive genres. Alfa, São Paulo, v.58, n.2, p.347-370, 2014.

- ABSTRACT: This work aims at discussing children's imaginary circulation through representations of discursive genres. More specifically, this research investigates how the circulation of such representations is shown in the children's projections for one or more of the addressees of their enunciations. The concept of discourse genre proposed by Bakhtin (2000) is adopted. The analysis of these selected children's written enunciations favored a specific and constitutive trait in order to define genre: the fact that the relatively stable types of enunciations have always an address and a direction (BAKHTIN, 2000). Starting from the concepts of addressing and of "other"- the latter one based on Authier-Revuz (1982, 1990) - it is suggested that, in spoken enunciations, individuals need to negociate with others elements (other wordings, other registers, other meanings and also other addressees) which constitute them and whichdetermine the emergence of their produced enunciation. The analysis of the children's enunciations showed that two important and interlinked facts should be observed: the non-univocity and the fluctuation about the addressing of the enunciations.

- KEYWORDS: Writing acquisition. Discourse genres. Intergenre relations. 


\section{REFERÊNCIAS}

ABAURRE, M. B. M.; FIAD, R. S.; MAYRINK-SABINSON, M. L. T. (Org.). Estilo e gênero na aquisição da escrita. Campinas: Komedi, 2003.

. Cenas de aquisição da escrita: o trabalho do sujeito com o texto. Campinas: Mercado de Letras, 1997.

AUTHIER-REVUZ. Heterogeneidade(s) enunciativa(s). Cadernos de Estudos Lingüísticos, Campinas, n.19, p.25-42, 1990.

Heterogeneité montrée et heterogeneité constitutive: elements pour une approche de l'áutre dans le discours. Revue de Linguistique, Bucarest, n.26, p.91-151, 1982.

BAKHTIN, M. A estética da criação verbal. Tradução de Paulo Bezerra. São Paulo: Martins Fontes, 2000.

BENVENISTE, E. Estrutura das relações de pessoa no verbo. In: Problemas de linguística geral I. Tradução de Maria da Glória Novak e Maria Luisa Salum. Campinas: Pontes, 1995. p.247-259.

BRANDÃO, H. H. N. Subjetividade, argumentação, polifonia: a propaganda da Petrobrás. São Paulo: Ed. da UNESP, 1998.

CORRÊA, M. L. G. Pressupostos teóricos para o ensino da escrita: entre a adequação e o acontecimento. Filologia e linguística portuguesa, São Paulo, n.9, p.201-211, 2007.

. Relações intergenéricas na análise indiciária de textos escritos. Trabalhos em Linguística Aplicada, Campinas, v.2, n.45, p.205-224, 2006.

O modo heterogêneo de constituição da escrita. São Paulo: Martins Fontes, 2004.

KOMESU, F. As relações intergenéricas constitutivas da escrita das home pages. In: ABAURRE, M. B. M.; MAYRINK-SABISON, M. L. T.; FIAD, R. S. (Org.). Estilo e gênero na aquisição da escrita. Campinas: Komedi, 2003. p.223-263.

PÊCHEUX, M. Análise automática do discurso. In: GADET, F.; HAK, T. (Org.). Por uma análise automática do discurso: uma introdução à obra de Michel Pêcheux. Campinas: Ed. da UNICAMP, 1990. p.61-162.

SCHERRE, M. M. P. Aspectos sincrônicos e diacrônicos do imperativo gramatical no português brasileiro. Alfa, São Paulo, v.51, n.1, p.189-222, 2007. 
A norma do imperativo e o imperativo da norma: uma reflexão sociolinguística sobre o conceito de erro. In: Doa-se lindos filhotes de poodle: variação lingüística, mídia e preconceito. São Paulo: Parábola, 2005. p.115143.

SOARES, M. B. Alfabetização: a (des)aprendizagem das funções da escrita. In: Alfabetização e letramento. São Paulo: Contexto, 2003. p.63-84.

Recebido em outubro de 2012.

Aprovado em maio de 2013. 